\title{
Correlation of Computed Tomography with Surgical Diagnosis in Lumbar Disc Disease
}

\author{
Robert Griebel, Stanley Tchang, Moe Khan and George Varughese
}

SUMMARY: The lumbar spines of one hundred patients with suspected lumbar disc herniations were analysed with computed tomography. The results are compared with the patients' surgical diagnosis and with myelography. CT scanning is with few exceptions the diagnostic procedure of choice in investigating lumbar disc disease.

RÉSUMÉ: Les rachis lombaires de cent (100) patients chez qui l'on soupçonnait fortement la présence d'une hernie discale ont été étudiés par scannographie (CT). Les résultats ont été confrontés à ceux de la myélographie et au diagnostic chirurgical final. La scannographie $(\mathrm{CT})$ s'est avérée, à peu d'exceptions près, la modalité diagnostique de choix pour l'investigation de la pathologie discale lombaire.

Can. J. Neurol. Sci. 1983; 10:248-25I

In 1979 Meyer et al first reported that herniated lumbar discs could be recognized by computerized tomography (CT). Since that time several articles have been published attesting to the diagnostic accuracy of CT with regard to disc herniations (Williams et al, 1980; Haughton et al, 1982). In a previous paper (Tchang et al, 1982), one of us reported on the first 52 patients of this series with emphasis on the comparative value of CT versus myelography. In an attempt to further define the diagnostic role of CT in patients with low back pain and sciatica, 100 consecutive patients with suspected lumbar disc herniations were followed through to surgery. All had a CT scan of the lumbar spine, and the results of this examination have been correlated with the myelographic findings and the ultimate surgical diagnosis.

\section{Materials ANd MethodS}

Between January 1979 and March 1982100 patients in the University Hospital, Saskatoon and the Saskatoon City Hospital underwent surgery for a herniated lumbar disc. Prior to surgery all 100 of these patients had a CT scan of their lumbar spine using the General Electric CT/T 8800 scanner. The first 13 patients were scanned following intrathecal metrizamide myelograms. Thereafter all had unenhanced CT scans with the gantry tilted parallel to the intervertebral disc space. Myelograms were carried out on 86 of the 100 patients. All but two of these were performed using $12 \mathrm{ml}$ of metrizamide $(220 \mathrm{mg}$. $\mathrm{I} / \mathrm{ml})$ injected by lumbar puncture.

The pathological findings encountered at surgery were obtained by retrieval of the surgeons operative summary or by direct conversation with the surgeon involved. In those cases in which there was a discrepancy between the radiographic and surgical findings the operative interpretation was assumed to be correct.

\section{RESULTS}

A herniated lumbar disc was found at surgery in 96 of the 100 patients. In 3 patients there were disc herniations at 2 levels. However there were 4 cases in which no disc was found at surgery despite both clinical and radiographic evidence of a disc herniation. The levels of the herniations were as follows: L3/4 - 5 discs, L 4/5 - 39 discs and LS/S1 - 55 discs.

Ninety-four of the $100 \mathrm{CT}$ scans revealed disc pathology which was in accordance with the findings at surgery (Fig. 1). Of the 6 scans not in agreement with the surgical findings there was one which was falsely negative, one was falsely positive, one was interpreted as equivocal and three scans were misinterpreted by the radiologist. The falsely negative scan suggested only a bulging annulus at $\mathrm{L} 3 / 4$ but both myelography and surgery confirmed a large herniated disc. In retrospect this was an error due to lack of experience in interpreting soft tissue densities (Fig. 2). The patient with the falsely positive scan did not have a protruded lateral disc as the scan suggested, but rather a small, cartilaginous osteophyte. The disc herniation considered to be an equivocal finding on the CT scan was positively identified both by myelography and at surgery. The three misinterpreted cases all had CT findings suggestive of a herniated disc but surgery revealed post operative fibrosis.

Seventy-four of the 86 patients who had myelograms had a radiographic diagnosis which was confirmed by the surgical findings. Forty-five myelograms were performed on patients with L5/S1 level disease. In six cases the results were either equivocal or failed to show the herniated disc (Fig. 3). This is a well recognized limitation of myelography at this level.

Thirty-five patients had myelograms with $L 4 / 5$ disc herniations and 5 of these were at variance with the operative findings. Two of these had equivocal findings which alone would not have justified surgery while another was interpreted as normal. Two myelograms at this level were misinterpreted - one as spondylosis and another as malignancy because of complete obstruction and a suggestion of adjacent bony destruction. CT scanning had correctly identified a massive disc herniation in this case.

At the L 3/4 level one of the five myelograms showed an equivocal disc herniation while the remaining four correctly identified the lesion.

From the Department of Clinical Neurological Sciences, University of Saskatchewan, Saskatoon.

Received January 3, 1983. Accepted in revised form July 21, 1983.

Reprint requests to: Dr. Robert Griebel, Department of Clinical Neurological Sciences, University Hospital, Saskatoon, Saskatchewan, Canada S7N 0X0. 


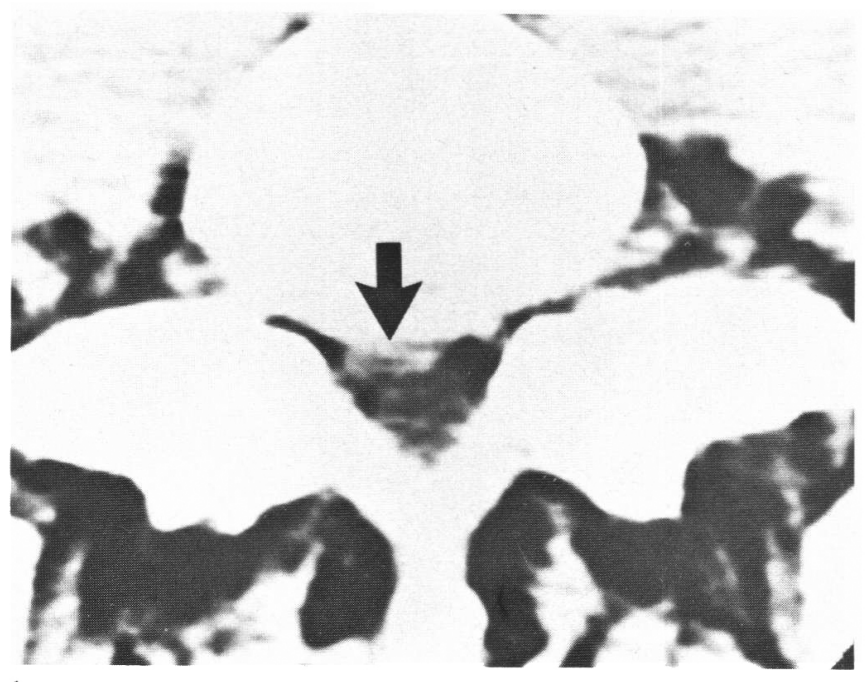

la
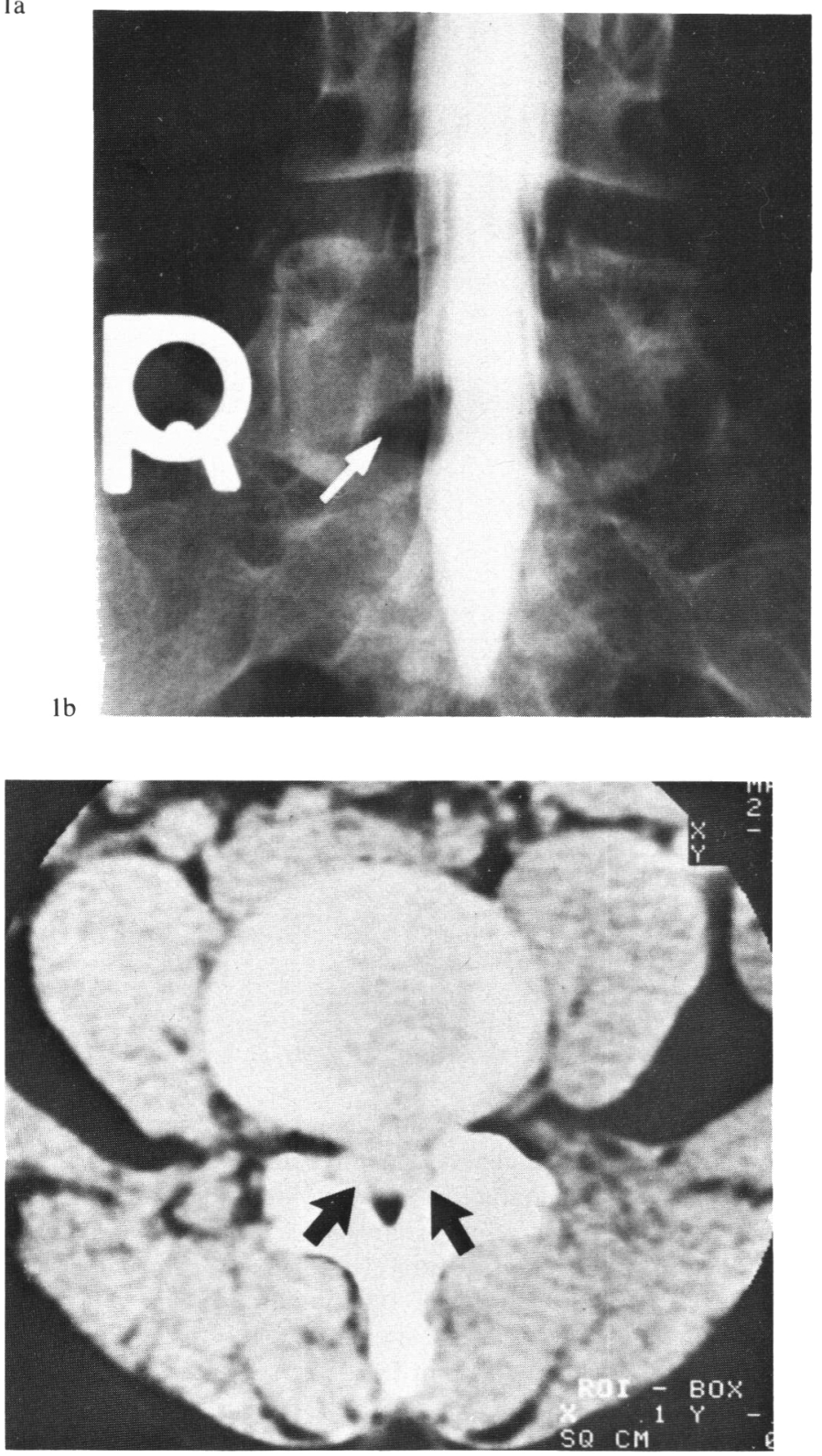

Figure 2-Large herniated central disc at L3/4 initially mistaken for a normal dural sac (Tchang et al, 1982 - reproduced with permission)
Figure $1-a)$ CT scan of a typical right lateral disc herniation (arrow) at the L5/SI level.

b) Myelogram of the same lesion showing the obliterated root sleeve.

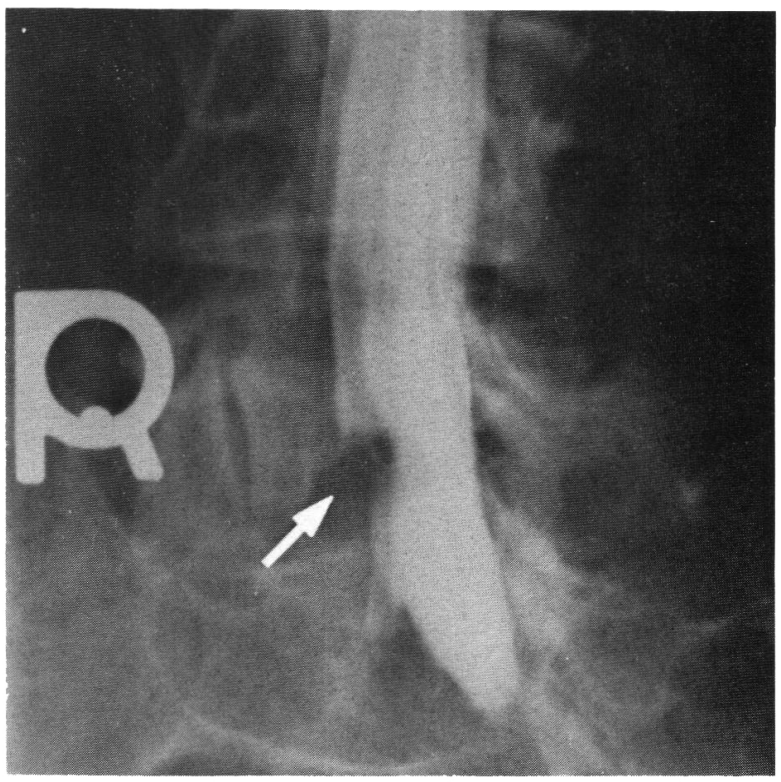

There were 12 patients in our series who had a previous history of disc surgery. In this group 4 of the 12 CT scans were incorrectly interpreted. Three of these showed findings suggestive of a herniated disc but in all three only post operative fibrosis was present at surgery (Fig. 4). The other scan showed an equivocal abnormality - the appearances being compatible with either a herniated disc or fibrosis.

The CT scan results of the group which had previous lumbar surgery are compared with the group having had no prior surgery in the accompanying table. Of the twelve myelograms in the re-operative group six correctly identified the surgical findings while the remaining six were equivocal.

\section{Discussion}

$\mathrm{CT}$ scanning shows a herniated nucleous pulposus as a posterior or posterolateral extension of the disc margin with displacement of the epidural fat, deformity of the dural sac and dislocation of root sleeves. Our series has shown that computerized tomography is an effective and accurate method of demonstrating herniated 

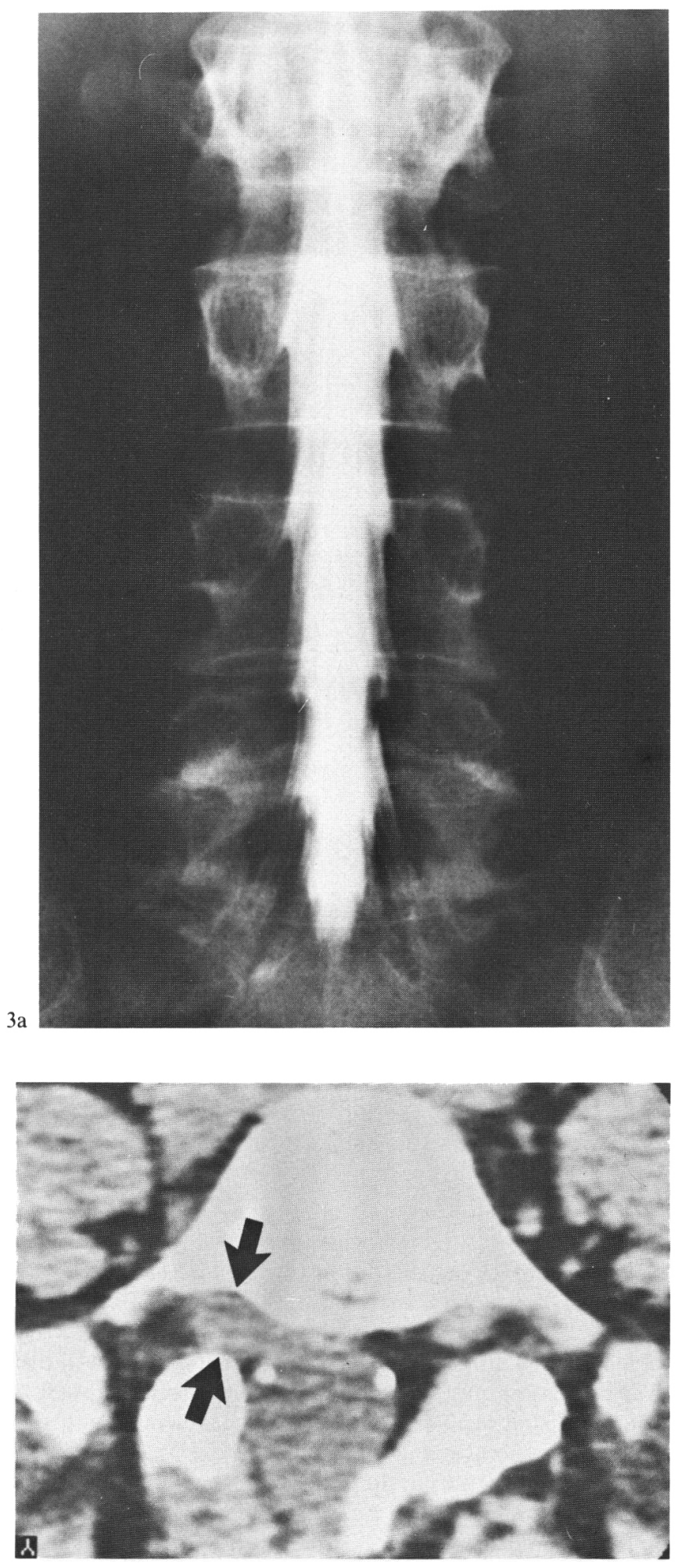

Figure 4-Localized post operative fibrosis simulating a herniated disc. (Tchang et al, 1982 - reproduced with permission)

nuclei pulposi, and is as reliable, if not more so, as myelography in the diagnosis of these herniations.

The main advantage of $\mathrm{CT}$ is that it is a noninvasive procedure. It avoids the infrequent but well documented complications associated with myelography — post lumbar puncture puncture

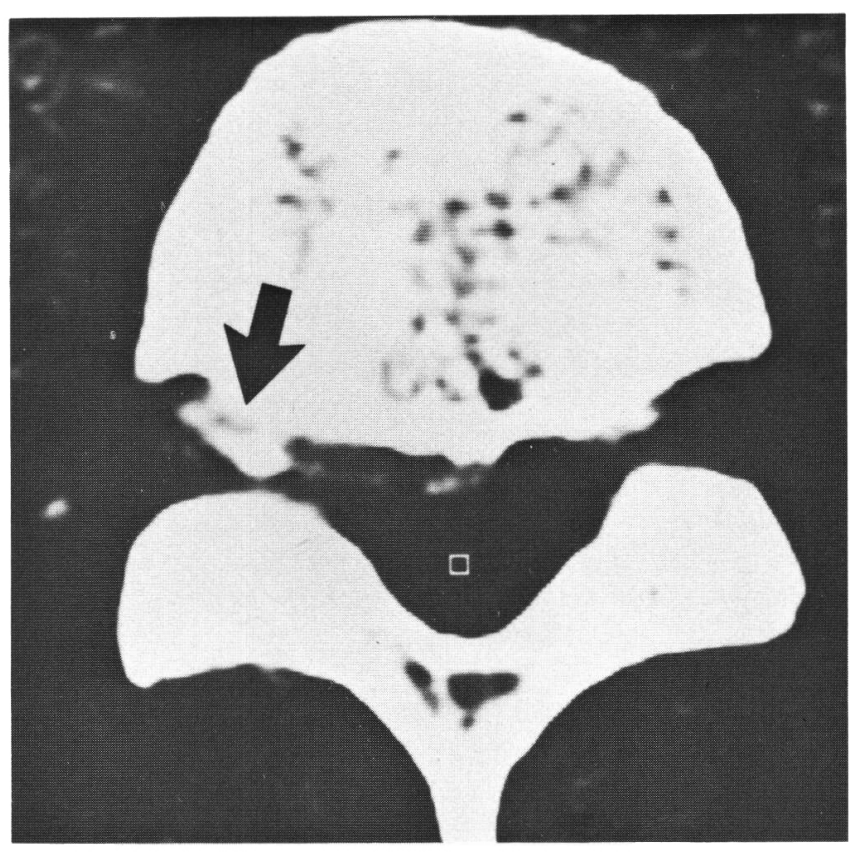

$3 b$

Figure 3 - a) Myelogram of a lateral L5/S1 disc herniation which failed to show a convincing lesion.

b) CT scan of the same patient showing the lateral extruded disc missed on myelogram.

Table: Effect of previous lumbar surgery on results of CT scanning

\begin{tabular}{lcc}
\hline \hline & $\begin{array}{c}\text { Patients with no } \\
\text { previous surgery }\end{array}$ & $\begin{array}{c}\text { Patients with } \\
\text { previous surgery }\end{array}$ \\
\hline
\end{tabular}

CT diagnosis agrees

with surgical findings

86

8

CT diagnosis disagrees with surgical findings

$\frac{2}{88} \quad \frac{4}{12}$

headache, infection, arachnoiditis, and adverse reactions to the contrast media. The cost and inconvenience of hospitalization necessary for myelography can be avoided. The radiation dose delivered with CT scanning is lower than with myelography 6 rads versus 10 rads (Haughton et al, 1982). A further advantage of CT is its ability to depict associated bony and soft tissue abnormalities such as lateral spinal stenosis, unsuspected bone lesions, paraspinal masses or facet joint disease.

Post operative epidural fibrosis remains a major diagnostic pitfall of CT scanning. As the epidural fat is replaced with scar it becomes increasingly difficult to identify the normal anatomical boundaries. It is thus suggested that in patients with a history of 
previous laminectomy both a CT scan and a myelogram be performed. A further diagnostic problem with CT can be the difficulty distinguishing a bulging annulus from a central disc herniation. There was however only one diagnostic error in this regard in this series. CT scanning is routinely limited to the S1 to L3 levels. Thus any associated pathology above the L3 level will be missed by scanning. The heavily built or obese individual may present a problem in that the quality of the scan is less than optimal.

This study supports the growing opinion that CT scanning is the diagnostic procedure of choice in investigating lumbar disc disease. It no longer is necessary to subject patients to myelography unless there is a discrepancy between clinical and CT findings or the CT findings are equivocal or if there has been previous lumbar surgery. However, the limited availability of CT scanners and the heavy schedule for the existing scanners continues to be a major impediment in using CT to screen patients with possible disc herniation.

\section{REFERENCES}

Haughton, V.M., Eldevik, O.P., Magnaes, B., Amundsen, P. (1982). A prospective comparison of computed tomography and myelography in the diagnosis of herniated lumbar discs. Radiology, 142, 103-110.

Meyer, G.A., Haughton, V.M., Williams, A.L. (1979). Diagnosis of herniated lumbar disc with computed tomography, N. Engl. J. Med., 301, 1166-1167.

Raskin, S.P., Keating, J.W. (1982). Recognition of lumbar disk disease: Comparison of myelography and computed tomography. Am. J. Neurorad., 3, 215-221.

Raskin, S. (1980). Introduction to computed tomography of the lumbar spine. Orthopedics, 3, 1011-1023.

Tchang, S.P.K., Howie, J.L., Kirkaldy-Willis, W.H., Paine, K.W.E., Moola, D. (1982). Computed tomography versus myelography in the diagnosis of lumbar disc herniation. J. Can. Assoc. Rad., 33, 15-20.

Williams, A.L., Haughton, V.M., Syvertsen, A. (1980). Computed tomography in the diagnosis of herniated nucleus pulposus. Radiology, 135, 95-99. 